\title{
Cinética e caracterização físico-química do fermentado de morango
}

\author{
Kinetic and physicochemical characterization of strawberry fermented \\ Cinética y caracterización fisicoquímica de fresa fermentada
}

Recebido: 18/08/2021 | Revisado: 22/08/2021 | Aceito: 25/08/2021 | Publicado: 27/08/2021

\author{
Isabela Leticia Pessenti \\ ORCID: https://orcid.org/0000-0002-5176-3134 \\ Universidade Cesumar, Brasil \\ E-mail: isabela.pessenti@unicesumar.edu.br \\ Pedro Henrique Brasileiro Santos \\ ORCID: https://orcid.org/0000-0002-8768-6134 \\ Universidade Cesumar, Brasil \\ E-mail: pedroagronomia98@gmail.com \\ Graziela Nunes \\ ORCID: https://orcid.org/0000-0001-5883-0267 \\ Universidade Estadual de Ponta Grossa, Brasil \\ E-mail: grazielaznunes@gmail.com \\ Paulo Ricardo de Los \\ ORCID: https://orcid.org/0000-0001-8841-0570 \\ Universidade Cesumar, Brasil \\ E-mail: Paulo.los@unicesumar.edu.br
}

\begin{abstract}
Resumo
O morangueiro é uma cultura exigente em relação a temperatura e condições climáticas, seu cultivo em ambiente protegido, produz frutos ricos em açúcares como sacarose, frutose e vitaminas, também possui poucos carboidratos, tornando-o muito saboroso aceito pelos consumidores. Sua comercialização também pode ser como geleia e polpa, sucos e fermentados. A preparação do fermentado de morango, não é uma bebida que apresenta grande comercialização no Brasil, apesar do conhecimento acerca de sua produção. Sendo assim, o presente trabalho tem como objetivo analisar a cinética e a caracterização físico-química do fermentado de morango em cultivo protegido com três cultivares de morango na Região dos Campos Gerais. O delineamento foi em inteiramente casualizado com 4 repetições cada. Sendo 3 tratamentos: testemunha, um tratamento com a levedura Saccharomyces cerevisae e Saccharomyces bayanus. Para as análises químicas, foi efetuado o teor de sólidos solúveis com refratômetro digital. A acidez titulável (\% de ácido cítrico) e o pH foram analisados também, assim como as variáveis fenólicas e o perfil cinético. Sólidos solúveis não foi significativo, para as variáveis fenólicas, a Saccharomyces bayanus apresentou os maiores teores quando comparado com os demais tratamentos, assim como demorou mais tempo para formar a produção no perfil cinético. Alguns autores relatam que os ácidos orgânicos presentes nas frutas interferem na atividade da cepa.
\end{abstract}

Palavras-chave: Bebida alcoólica; Vinho de morango; Ecologicamente sustentável.

\begin{abstract}
Strawberry is a demanding crop in relation to temperature and climatic conditions, its cultivation in a protected environment, produces fruits rich in sugars such as sucrose, fructose and vitamins, it also has few carbohydrates, making it very tasty accepted by consumers. Its commercialization can also be as jelly and pulp, juices and fermented. The preparation of the fermented strawberry is not a drink that is widely commercialized in Brazil, despite the knowledge about its production. Thus, the present work aims to analyze the kinetics and the physicochemical characterization of strawberry fermented in protected cultivation with three strawberry cultivars in the Campos Gerais Region. The design was completely randomized with 4 repetitions each. Three treatments: control, a treatment with the yeast Saccharomyces cerevisae and Saccharomyces bayanus. For chemical analysis, the content of soluble solids was performed with a digital refractometer. Titratable acidity (\% citric acid) and $\mathrm{pH}$ were also analyzed, as well as phenolic variables and kinetic profile. Soluble solids was not significant, for phenolic variables, Saccharomyces bayanus presented the highest levels when compared to other treatments, as well as it took longer to form the production in the kinetic profile. Some authors report that organic acids present in fruits interfere with the activity of the strain.
\end{abstract}

Keywords: Alcoholic beverage; Strawberry wine; Ecologically sustainable.

\section{Resumen}

La fresa es un cultivo exigente en cuanto a temperatura y condiciones climáticas, su cultivo en un ambiente protegido, produce frutos ricos en azúcares como sacarosa, fructosa y vitaminas, además tiene pocos carbohidratos, por lo que es 
muy sabroso aceptado por los consumidores. Su comercialización también puede ser en gelatina y pulpa, jugos y fermentados. La preparación de la fresa fermentada no es una bebida que se comercialice ampliamente en Brasil, a pesar del conocimiento sobre su producción. Así, el presente trabajo tiene como objetivo analizar la cinética y la caracterización fisicoquímica de la fresa fermentada en cultivo protegido con tres cultivares de fresa en la Región de Campos Gerais. El diseño fue completamente al azar con 4 repeticiones cada uno. Tres tratamientos: control, un tratamiento con la levadura Saccharomyces cerevisae y Saccharomyces bayanus. Para el análisis químico, el contenido de sólidos solubles se realizó con un refractómetro digital. También se analizaron la acidez titulable (\% ácido cítrico) y el $\mathrm{pH}$, así como las variables fenólicas y el perfil cinético. Los sólidos solubles no fueron significativos, para las variables fenólicas, Saccharomyces bayanus presentó los niveles más altos en comparación con otros tratamientos, así como también tomó más tiempo para formar la producción en el perfil cinético. Algunos autores informan que los ácidos orgánicos presentes en las frutas interfieren con la actividad de la cepa.

Palabras clave: Bebida alcohólica; Vino de fresa; Ecológicamente sustentable.

\section{Introdução}

O morango (Fragaria $\times$ ananassa) é uma angiosperma, pertencente à família Rosaceae, essa grande e diversificada família que inclui muitas espécies produtoras de frutos de estimado valor para o consumo humano, como maçãs, pêssegos, framboesas e amoras. O morangueiro é uma cultura herbácea estolonífera perene que se desenvolvem a partir das gemas basais das folhas, crescem sobre a superfície do solo e tem a capacidade de dar origem a novas raízes, é pouco exigente quanto ao clima, embora prefira climas temperados, a temperatura afeta o desenvolvimento vegetativo, a produção e qualidade do morango, sendo o principal fator limitante da cultura, pois, quando elevada, o morango torna-se muito ácido, pobre em sabor, em aroma e de menor consistência. O frio, durante a madrugada, favorece a obtenção de frutos com sabor e aroma, essas características fazem que a cultura seja muito sensível a falta de água. É um fruto que apresenta estrutura frágil e alta atividade respiratória, sendo rico em diversas vitaminas C, A, E, B5, B6. Pertence ao grupo das pequenas frutas, o morango é a espécie mais explorada no Brasil (Antunes; Carvalho; dos Santos, 2011).

O morango é um pseudofruto muito apreciado pelo seu sabor, aroma e propriedades nutricionais. É uma fonte potencial de compostos bioativos, com ênfase para os compostos fenólicos e Vitamina C, tais compostos apresentam diversas funções biológicas, dentre elas, atividade antioxidante, trazendo benefícios para a saúde. A cultura deste pseudofruto é a base da economia de muitos municípios, especialmente, nas regiões Sul e Sudeste do Brasil, representando 90\% da superfície cultivada no país. Existe um importante interesse em relação à ingestão de alimentos ricos em minerais na prevenção de várias doenças, mesmo abrangendo apenas cerca de 4-6\% do corpo humano, os minerais se mostram fatores essenciais na alimentação. Os principais minerais zinco, ferro, cobre, manganês, silício, flúor, iodo e cromo (Özcan,2004). A “qualidade do morango é fundamental para sua comercialização e diversos aspectos de manejo, como sistema de cultivo, condições edafoclimáticas, adubação, cultivar, entre outros, influenciam na qualidade das frutas" (Carvalho, 2013).

O Brasil é um importante produtor mundial de frutas, no entanto, o país apresenta altos índices de desperdício, principalmente durante o processo de comercialização, por se tratar de matéria-prima facilmente suscetível à degradação. Por esse motivo, são descartadas diariamente grandes quantidades de frutas que não apresentam qualidade para o consumo in natura, pois apresentam defeitos nas cascas, tamanhos, coloração, consistência, entre outros fatores (Tessaro et al., 2010). O principal mercado do morango em âmbito local é o da fruta fresca, mas há também forte demanda pela fruta em processo de industrialização, na forma de polpa congelada, sorvetes, geleias, gelatinas, xaropes, chás, compotas e sucos, bebidas alcóolicas, que aumentam sua validade e agregam valor econômico ao mesmo. A produção nacional de morangos se expande a cada ano, com predominância do cultivo em pequenas propriedades rurais, por se tratar de exploração que agrega mão de obra familiar, possui grande importância econômica e social, caracterizando-se em excelente fonte de renda para pequenas propriedades.

Várias técnicas têm sido desenvolvidas e utilizadas a fim de aumentar a vida pós-colheita desses frutos, assim como para permitir o seu aproveitamento integral. Dentre essas técnicas, destaca-se a fermentação alcóolica, como uma alternativa bastante viável para o aproveitamento de frutos, a elaboração de novos produtos e agregação de valor (Song et al., 2016). 
Diversas frutas têm boas características sensoriais para vinhos e, aliada à necessidade de se ampliar as suas produções e consumo em diversos países, a produção destes "vinhos" alternativos, tem sido bastante pesquisada e incentivada (Silva et al., 2008). A elaboração do fermentado a partir da diversidade das frutas, apresentam-se como alternativa no desenvolvimento de tecnologias para a obtenção de produtos derivados com maior vida de prateleira e valor agregado e ainda constituem produtos promissores, devido à tendência de aceitação em pesquisas de consumo (Fagundes et al., 2015).

De acordo com o Ministério da Agricultura Pecuária e Abastecimento, fermentado de fruta é a bebida com graduação alcoólica de 4 a $14 \%$ em volume, a $20{ }^{\circ} \mathrm{C}$, obtida da fermentação alcoólica do mosto de fruta sã, fresca e madura (Brasil, 2009). A fermentação é uma tecnologia eficiente e de baixo custo, representando um novo ramo para a fruticultura industrial e para a elaboração de novas bebidas fermentadas (Asquieri et al., 2008). Praticamente todas as frutas ou materiais açucarados podem ser utilizados na produção de bebidas fermentadas, desde que adequadamente corrigidos os teores de umidade e sais nutritivos para o fermento, no Brasil, dispõe-se de uma grande diversidade de frutas com produção praticamente por todo o ano. Frutas como manga (Mangifera indica L.), jabuticaba (Myrciaria spp.), goiaba (Psidium guajava L.), amora (Morus nigra, M. alba L.), acerola (Malpighia punicifolia L.), entre outras, nativas ou plantadas em pomares não comerciais são praticamente perdidas tal a abundância da produção (Asquieri et al., 2009; Silva et al., 2008).

A principal matéria prima para a fabricação de vinhos e fermentados é a uva, porém com busca de agregar valores a diferentes frutas, e a avanços tecnológicos na vinicultura têm promovido a busca de novos processos para a fabricação de bebidas fermentadas de frutas, como o fermentado de morango (vinho da fruta) é produzido em pequena escala e ainda pouco comercializado, é necessário fazer as análises do mesmo, entre elas, a físico-química, para verificar a qualidade desse produto.

A preparação do fermentado de morango, não é uma bebida que apresenta grande comercialização no Brasil, apesar do conhecimento acerca de sua produção. Os fermentados de frutas como morango e laranja não são tão comuns quanto o vinho proveniente da uva, como o fermentado do morango é pouco divulgado é interessante o estudo mais aprofundado de sua produção, a fabricação de um fermentado alcoólico de morango poderá ser uma boa alternativa para o aproveitamento do fruto e evitar o desperdício desenvolvendo o fermentado e testando a aceitação do consumidor. A qual requer uma adaptação dos processos de produção, pois, as operações aplicadas aos processos de fermentados de frutas são de produção de vinho de uva.

O presente trabalho teve como objetivo analisar a cinética e a caracterização físico-química do fermentado de morango da variedade Albion avaliando as características de cor, sabor, acidez entre outros fatores. Devido ao morango apresentar características de ser muito rico em sacarose, frutose e pobre em carboidratos o torna atrativo na utilização e produção de um fermentado alcoólico sendo que a principal reação que ocorre na fermentação é a da Glicose "Frutose, sacarose" em etanol "Álcool” e $\mathrm{CO}_{2}=$ Gás carbônico que por meio de reações químicas leveduras e outros microrganismos como Saccharomyces fazem a síntese da glicose transformando em etanol e $\mathrm{CO}_{2}$.

\section{Metodologia}

O experimento foi conduzido no Laboratório de Agronomia no Centro Universitário de Maringá - Polo Ponta Grossa - PR, com os frutos de morango (Fragaria $\times$ ananassa) variedade San Andreas. Os frutos foram adquiridos diretamente com o produtor, logo após a colheita. O delineamento foi em inteiramente casualizado com 4 repetições cada. Sendo 3 tratamentos: testemunha, um tratamento com a levedura Saccharomyces cerevisae e Saccharomyces bayanus.

Para as análises químicas, foi efetuado o teor de sólidos solúveis com refratômetro digital Modelo 103 (Biobrix, São Paulo, Brasil). A acidez titulável (\% de ácido cítrico) e o pH foram analisados através de mini titulador modelo HI 84532 (Hanna, Woonsocket, Rhode Island, EUA).

Vinte e quatro horas após a colheita, os frutos foram pesados $400 \mathrm{~g}$ para cada repetição, conforme Pessenti et al. (2019) para fazer o fermentado. Em seguida, foram esmagadas manualmente e acondicionadas em mini tanques de 
fermentação. Posteriormente, foi adicionado metabissulfito de potássio $10 \mathrm{~g} \mathrm{hL}^{-1} \mathrm{e}$ após uma hora foi adicionado a levedura $\mathrm{S}$. cerevisiae e bayanus na proporção de $10 \mathrm{~g} 100 \mathrm{~L}^{-1}$. Na testemunha não foi adicionado nenhuma levedura. A fermentação alcóolica foi acompanhada por meio da medição da densidade à $20^{\circ} \mathrm{C}$ e da pesagem diariamente até que houvesse a estabilização, momento em que também foi realizado a remontagem do mosto. Após dez dias de fermentação alcoólica foi realizada a descuba, com auxílio de sacos de voil. A descuba foi determinada quando houver estabilização por três dias consecutivos da massa dos mini tanques de fermentação.

Foram unidas duas repetições formando amostras compostas, resultando em 3 repetições. Após este processo, ocorrerá a fermentação lenta, onde foi mensurada a massa diariamente. Após a trasfega, ocorreu a fermentação malolática, sendo que o término foi determinado pela cromatografia de ácido málico. Foi adicionado metabissulfito de potássio dissolvido $\left(10 \mathrm{~g} 100 \mathrm{~L}^{-1}\right)$ e ocorreu a estabilização tartárica em câmara fria, por 30 dias com controle de temperatura $\left(0^{\circ} \mathrm{C}\right)$. Decorrida a estabilização tartárica, foi realizado o engarrafamento manual, rotulagem e armazenamento em ambiente refrigerado. Após esse processo foi realizado as análises químicas, fenólicas e determinação do perfil cinético do fermentado de morango (Pessenti et al., 2021).

Para a determinação do teor de polifenóis totais, foi seguido o método de Singleton e Rossi (1965), que utiliza o reagente de Folin Ciocalteau e uma curva de calibração com ácido gálico. Pesou-se $1 \mathrm{~g}$ de cascas frescas que foram colocadas em tubos falcon, adicionado de $0,4 \mathrm{~mL}$ de uma solução de álcool metílico $50 \% \mathrm{v} / \mathrm{v}$. Os frascos foram tampados com papel filme e permaneceram em BOD a $30^{\circ} \mathrm{C}$ durante 24 horas. Após este período, o extrato foi separado em frasco de vidro. Adicionou-se $0,1 \mathrm{~mL}$ de solução de metanol, para enxaguar as cascas. Após isso, mais $0,4 \mathrm{~mL}$ de solução hidroalcoólica foi adicionada aos tubos falcons, para então as cascas passarem pela extração, em BOD a $0^{\circ} \mathrm{C}$, por 24 horas. Posteriormente, o extrato foi homogeneizado com o extrato retirado anteriormente, e repetiu-se o enxágue das cascas. Ao final do processo, obteve-se um extrato de $1 \mathrm{~mL}$ para cada amostra.

Em seguida, procedeu-se a reação com o reagente Folin-Ciocalteau. Em um tubo de ensaio, adicionou-se 7,9 mL de água destilada; $0,1 \mathrm{~mL}$ da solução padrão; $0,50 \mathrm{~mL}$ do reagente de Folin-Ciocalteau, e após 3 minutos, 1,50 mL de solução de carbonato de sódio a $20 \%$. As amostras foram homogeneizadas e permaneceram no escuro por 2 horas, para completar a reação. Em seguida, foram realizadas as leituras da absorbância das amostras a um comprimento de $760 \mathrm{~nm} \mathrm{em}$ espectrofotômetro modelo UV 1650 PC (Shimadzu, Kyoto, Japão). Para as leituras obtidas, ajustou-se uma curva de regressão linear. Para a obtenção da concentração de polifenóis totais nos extratos de cascas de uva, realizou-se o mesmo procedimento de reação, com o reagente Folin-Ciocalteu, descrito para a curva de calibração. Exceto para o fato de que as soluções extratos tiveram que ser diluídas na proporção 1:10. As leituras obtidas com os extratos foram interpoladas na curva padrão, e os resultados foram expressos em mg equivalente de ácido gálico $\mathrm{L}^{-1}$.

O método utilizado para a quantificação antocianinas totais foi descrito por Lee e Francis (1972), com modificações. O conteúdo de $1 \mathrm{~g}$ de casca foi retirado do ultrafreezer e macerado em cadinhos de porcelana com $10 \mathrm{~mL}$ de solução extratora (50\% de etanol 95\% + 50\% de ácido clorídrico 1,5 M). Com as amostras totalmente maceradas, o conteúdo líquido foi armazenado em tubo de ensaio protegido da luz (coberto por papel alumínio), realizando-se em seguida a lavagem do restante do macerado preso ao cadinho, adicionando-se mais $15 \mathrm{~mL}$ da solução extratora (Pessenti et al., 2021).

Os tubos foram mantidos sob refrigeração a $4^{\circ} \mathrm{C}$ por 20 horas e posteriormente, o extrato foi filtrado, lavando-o com $25 \mathrm{~mL}$ da solução extratora, deixando o total do extrato em frasco coberto com papel alumínio por duas horas. Em seguida, foram retirados $2 \mathrm{~mL}$ do extrato, adicionando-se $10 \mathrm{~mL}$ da solução extratora e posterior agitação em vortex. A leitura da amostra foi feita em espectrofotômetro modelo UV 1650 PC (Shimadzu, Kyoto, Japão) a $535 \mathrm{~nm}$ para a determinação do teor de antocianinas, sendo os valores expresso em $\mathrm{mg}$ de antocianinas por $100 \mathrm{~g}$ de material vegetal. Para quantificação do teor de antocianinas utilizou-se a equação $1(\mathrm{FD} * \mathrm{VA}) * 98,2^{-1}$, em que VA = valor da absorbância e FD = fator de diluição. Para o teor de flavonoides totais utilizou-se a equação (FD*VA) $* 76,6^{-1}$. 
A normalidade dos dados foi testada pelo teste de Kolmogorov-Smirnov ao nível de 5\% de significância. Será empregado a análise de variância (ANOVA) e as médias foram comparadas através do teste Scott Knott, ao nível de 5\% de probabilidade. O software utilizado será o R (R Core Team, 2021), utilizando o pacote ExpDes.pt.

\section{Resultados e Discussão}

Na Figura 1 observa-se que não houve diferença significativa entre os tratamentos para a variável sólidos solúveis totais.

Figura 1 - Sólidos Solúveis Totais ('Brix) para o fermentado de morango cv. San Andreas na safra 2019/20. TEST: testemunha (controle); SC: Saccharomyces cerevisae $10 \mathrm{~g} \mathrm{hL}^{-1}$; SB: Saccharomyces bayanus $10 \mathrm{~g} \mathrm{hL}^{-1}$. Médias seguidas de mesma letra não diferem entre si pelo teste de Scott Knott $(\mathrm{p} \leq 0,05)$.

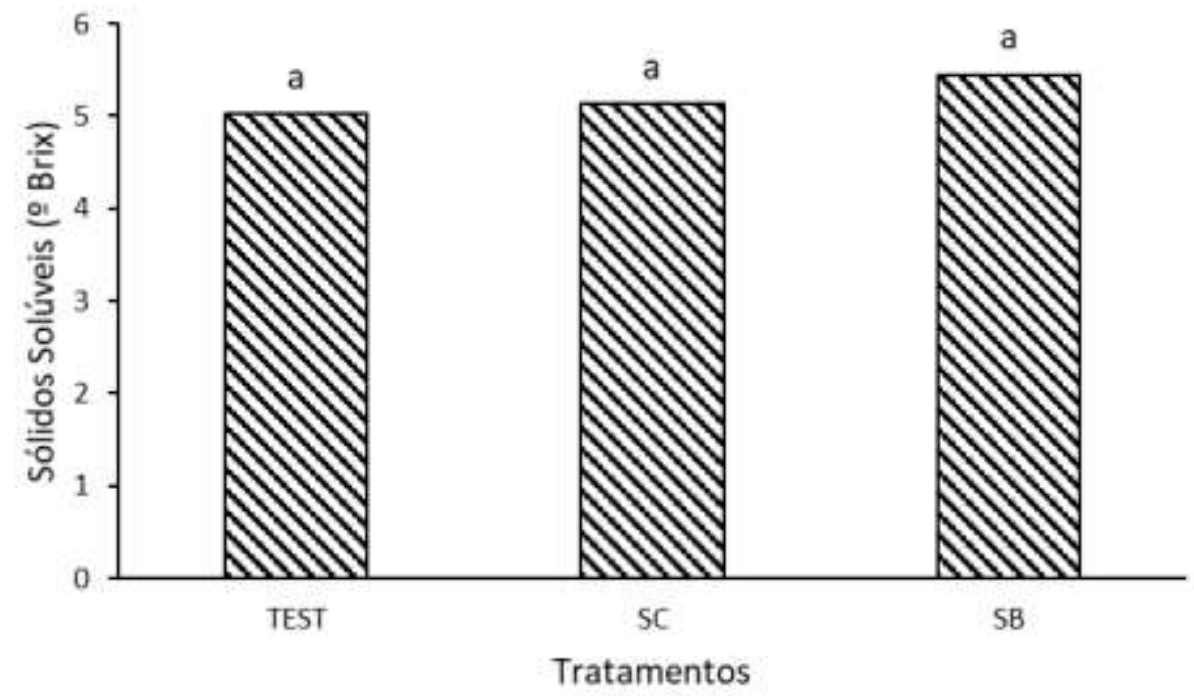

Fonte: Autores.

Na Figura 2, o tratamento com a S. bayanus apresentou maior acidez. Na Figura 3, os tratamentos com a S. cerevisae e S. bayanus apresentaram menor valor de pH quando comparado com a testemunha. Januszek et al. (2020) testaram essas duas cepas em sidras oriundas de 3 cultivares de maçã, as leveduras apresentaram pH mais baixo quando comparado com a testemunha. Ressalta-se que atividade destas cepas são mais favoráveis em pH mais baixos que 3,0.

O ácido cítrico é o principal ácido orgânico no morango. Algumas espécies de leveduras são capazes de assimilar o ácido cítrico. As cepas de S. cerevisiae mostram várias habilidades para degradar o ácido málico durante a fermentação alcoólica. Os resultados obtidos sugerem que o perfil de ácidos orgânicos no morango foi significativamente diferente porque, por exemplo, no caso dos mostos fermentados com S. bayanus, a acidez titulável após a fermentação aumentou no mosto. Isso sugere que inicialmente continha alguns ácidos que poderiam ser fermentados por aquela cepa de levedura a fundo (Januszek et al., 2020; Tarko et al., 2018). 
Figura 2 - Acidez titulável (\% ácido cítrico) para o fermentado de morango cv. San Andreas na safra 2019/20. TEST: testemunha (controle); SC: Saccharomyces cerevisae $10 \mathrm{~g} \mathrm{hL}{ }^{-1}$; SB: Saccharomyces bayanus $10 \mathrm{~g} \mathrm{hL}^{-1}$. Médias seguidas de mesma letra não diferem entre si pelo teste de Scott Knott $(\mathrm{p} \leq 0,05)$.

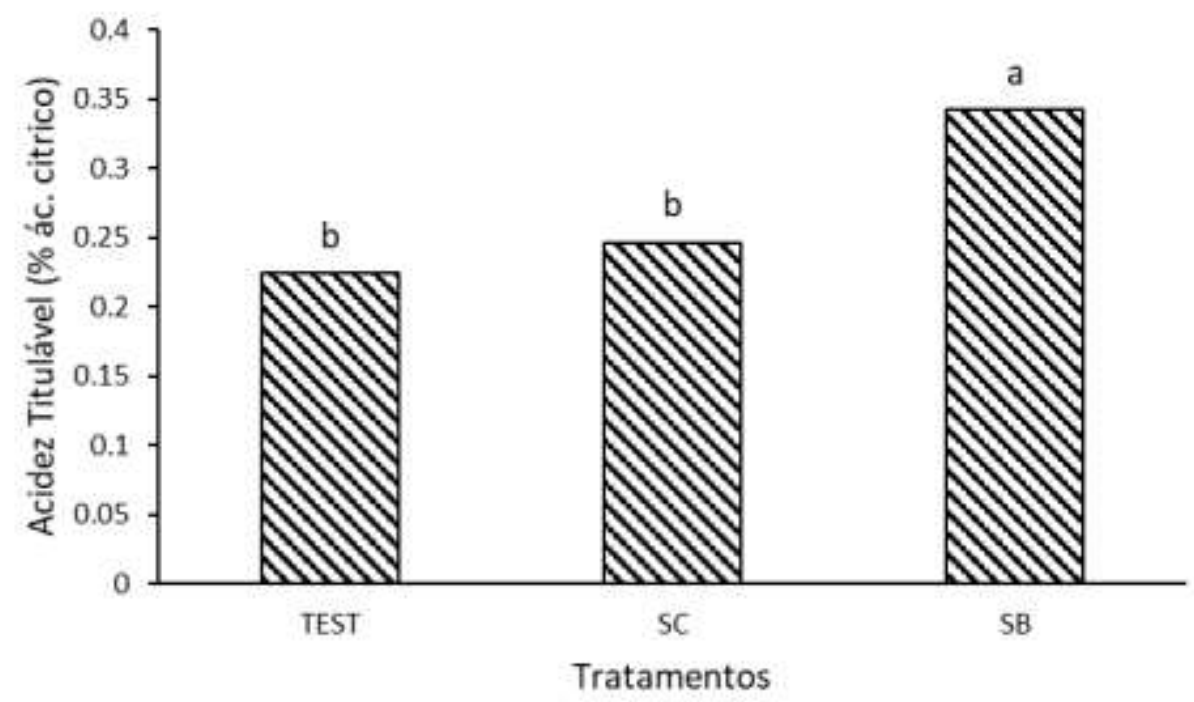

Fonte: Autores.

Figura 3 - Variável pH para o fermentado de morango cv. San Andreas na safra 2019/20. TEST: testemunha (controle); SC: Saccharomyces cerevisae $10 \mathrm{~g} \mathrm{hL}^{-1}$; SB: Saccharomyces bayanus $10 \mathrm{~g} \mathrm{hL}^{-1}$. Médias seguidas de mesma letra não diferem entre si pelo teste de Scott Knott $(\mathrm{p} \leq 0,05)$.

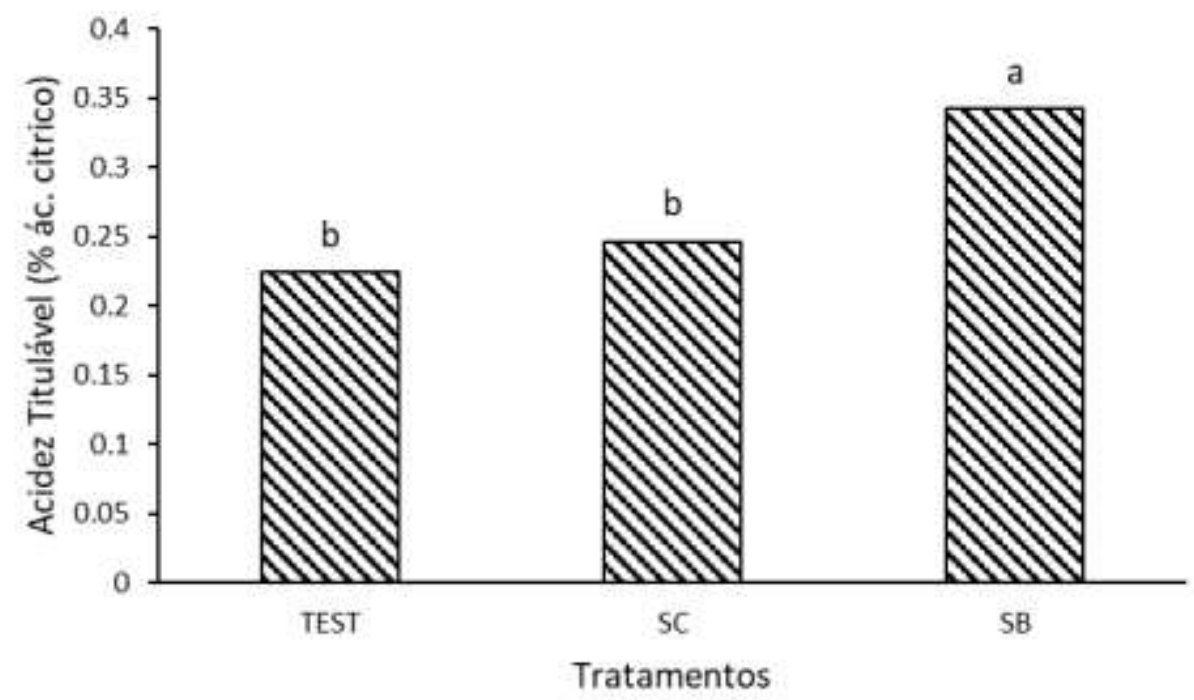

Fonte: Autores.

Na Figura 4, nota-se que a Saccharomyces cerevisae apresentou mais teor de flavonoides, enquanto na Figuras 5 e 6 , para os teores de antocianinas e polifenóis totais, a Saccharomyces bayanus apresentou os maiores valores, respectivamente. 
Figura 4 - Flavonoides totais (mg $100 \mathrm{~g}^{-1}$ ) para o fermentado de morango cv. San Andreas na safra 2019/20. TEST: testemunha (controle); SC: Saccharomyces cerevisae $10 \mathrm{~g} \mathrm{hL}^{-1}$; $\mathrm{SB}$ : Saccharomyces bayanus $10 \mathrm{~g} \mathrm{hL}^{-1}$. Médias seguidas de mesma letra não diferem entre si pelo teste de $\operatorname{Scott} \operatorname{Knott}(\mathrm{p} \leq 0,05)$.

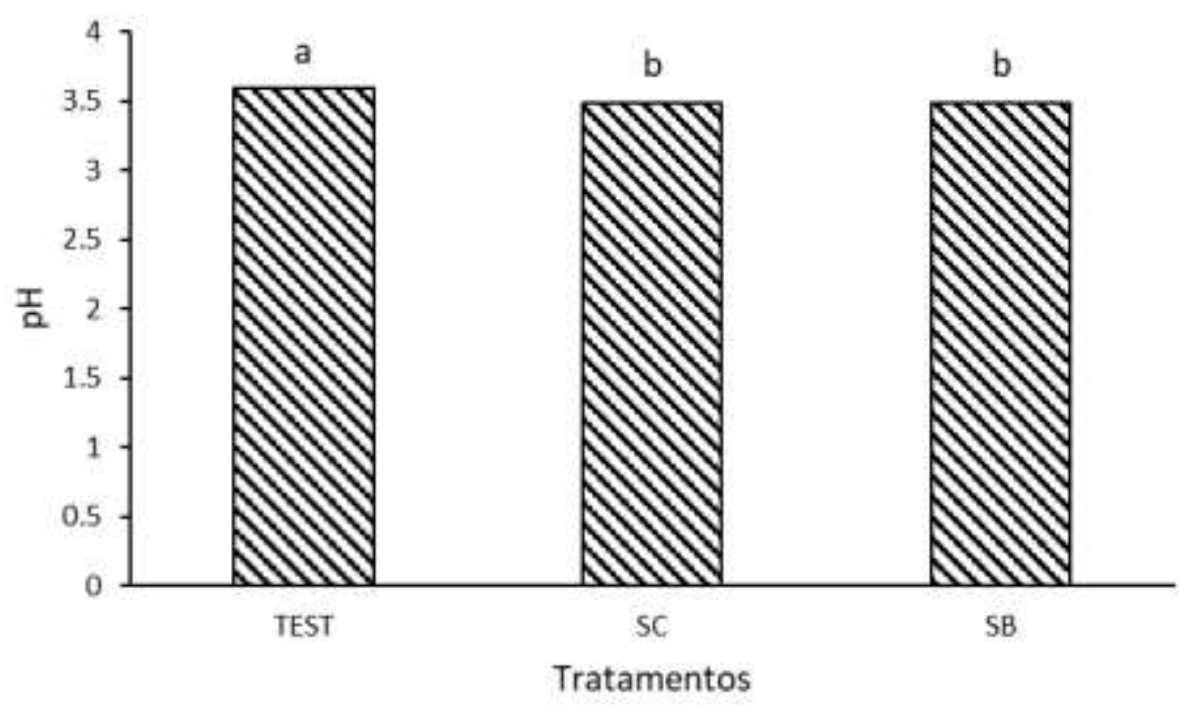

Fonte: Autores.

Figura 5 - Antocianinas totais (mg $100 \mathrm{~g}^{-1}$ ) para o fermentado de morango cv. San Andreas na safra 2019/20. TEST: testemunha (controle); SC: Saccharomyces cerevisae $10 \mathrm{~g} \mathrm{hL}^{-1}$; $\mathrm{SB}$ : Saccharomyces bayanus $10 \mathrm{~g} \mathrm{hL}^{-1}$. Médias seguidas de mesma letra não diferem entre si pelo teste de $\operatorname{Scott} \operatorname{Knott~}(p \leq 0,05)$.

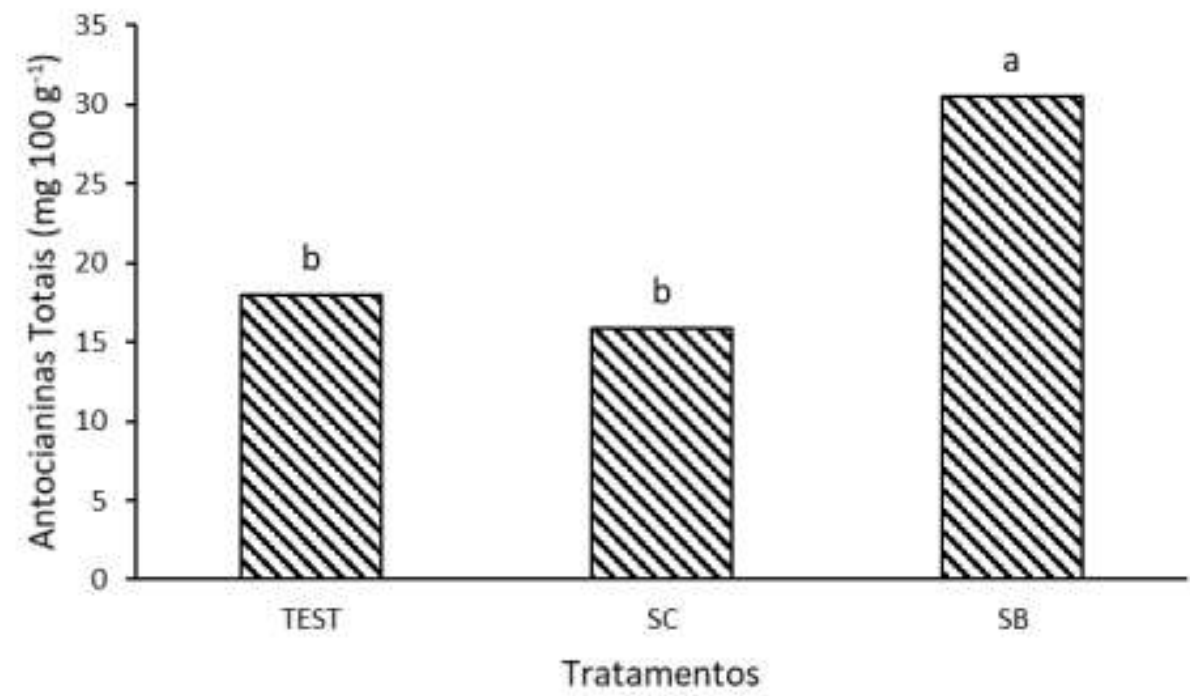

Fonte: Autores. 
Figura 6 - Polifenóis totais (mg eag L ${ }^{-1}$ ) para o fermentado de morango cv. San Andreas na safra 2019/20. TEST: testemunha (controle); SC: Saccharomyces cerevisae $10 \mathrm{~g} \mathrm{hL}^{-1}$; SB: Saccharomyces bayanus $10 \mathrm{~g} \mathrm{hL}^{-1}$. Médias seguidas de mesma letra não diferem entre si pelo teste de Scott $\operatorname{Knott}(\mathrm{p} \leq 0,05)$.

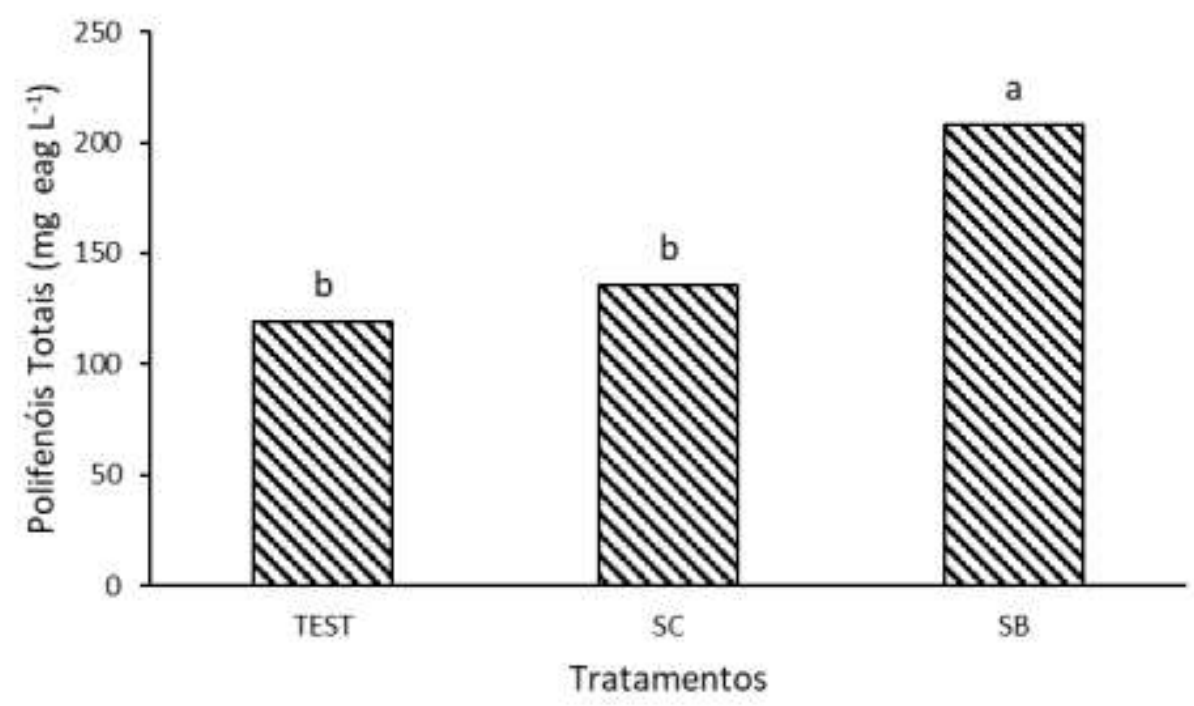

Fonte: Autores.

Na Figura 7 observa-se o perfil cinético dos 3 tratamentos, a Saccharomyces bayanus demorou mais tempo para obter maior formação de produto em função do tempo. Tarko et al. (2018) mostrou que o processo de fermentação foi mais lento no mosto inoculado com $S$. bayanus em comparação com outras leveduras deve-se ao fenômeno de que $S$. bayanus usa açúcares para a síntese de compostos voláteis com alta temperatura de ebulição ao invés de dióxido de carbono ou pequenas moléculas de voláteis que poderiam ser facilmente perdidas durante a fermentação ou usadas para a formação de compostos mais complexos. Substâncias, isto é, ésteres (Januszek et al., 2020).

Figura 7 - Perfil cinético para o fermentado de morango cv. San Andreas na safra 2019/20. TEST: testemunha (controle); SC: Saccharomyces cerevisae $10 \mathrm{~g} \mathrm{hL}^{-1}$; $\mathrm{SB}$ : Saccharomyces bayanus $10 \mathrm{~g} \mathrm{hL}^{-1}$.

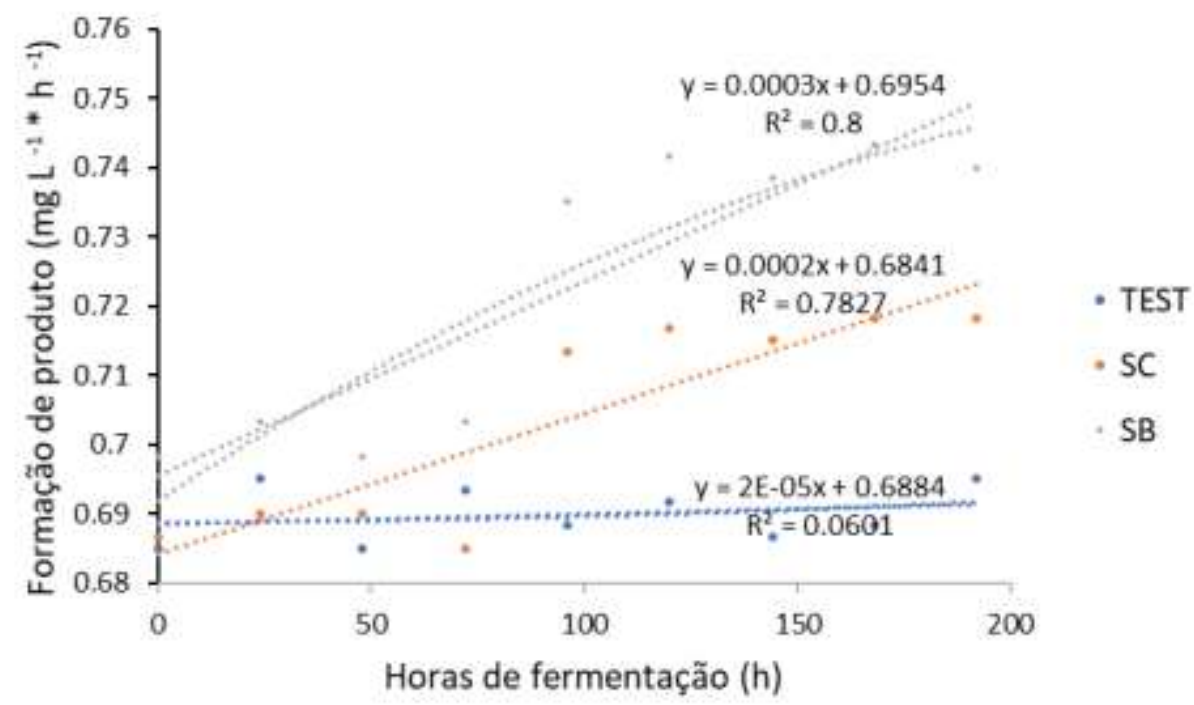

Fonte: Autores. 
Na Figura 8 observa-se que a turbidez e cor foram significativas a 5\% de probabilidade pelo teste de Tukey. Pode-se observar que a amostra Saccharomyces bayanus possui cor menos intensa se comparada as amostras Saccharomyces cerevisae e testemunha. Um comportamento similar pode ser observado para a turbidez, onde a amostra Saccharomyces bayanus se apresenta menos turva se comparada as demais.

O mesmo pode ser observado no gráfico teia. No mesmo gráfico observa-se um perfil sensorial similar para todas as amostras, onde seguem a mesma linha. Apesar de não haver diferença significativa, avaliando-se as linhas, a amostra Saccharomyces bayanus $10 \mathrm{~g} \mathrm{hL}^{-1}$ possui um perfil aromático menos intenso que as demais. Com uma menor qualidade de aromas.

Figura 8 - Análise Sensorial para o fermentado de morango cv. San Andreas na safra 2019/20. TEST: testemunha (controle); $\mathrm{SC}$ : Saccharomyces cerevisae $10 \mathrm{~g} \mathrm{hL}{ }^{-1}$; SB: Saccharomyces bayanus $10 \mathrm{~g} \mathrm{hL}^{-1}$.

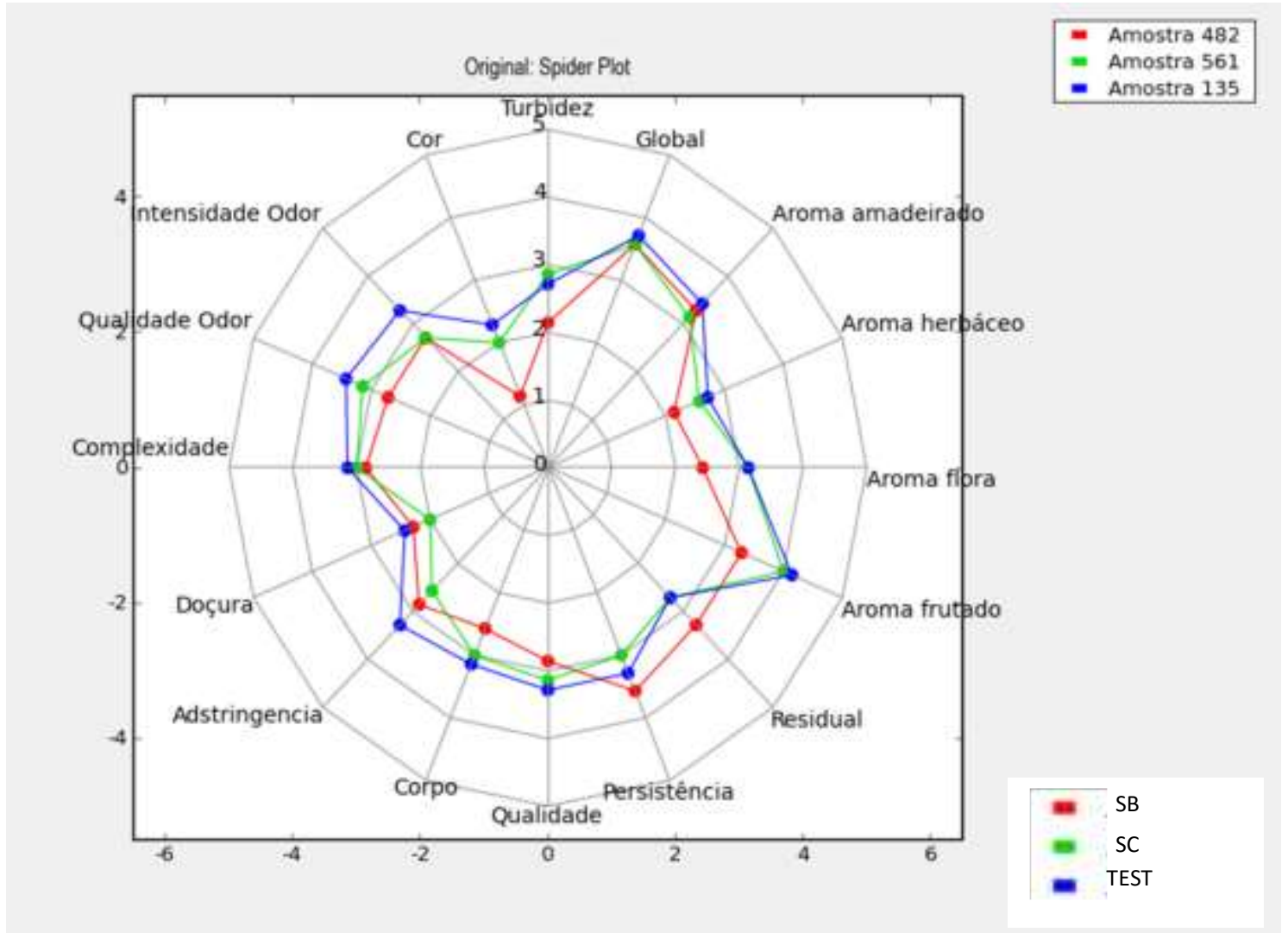

Fonte: Autores.

\section{Conclusão}

A pesquisa confirmou a hipótese de que vários tipos de fermentação influenciam significativamente a composição química dos mostos fermentados, bem como o perfil volátil e as características sensoriais das destiladas obtidas, e que S. bayanus é uma cepa de levedura apropriada para a produção de fermentado de morango. Nos mostos fermentados, o período de adaptação dos microrganismos às condições de fermentação foi o mais longo e a fermentação mais lenta.

No entanto, mais estudos devem ser realizados para avaliar se os perfis obtidos de compostos podem estar associados à presença de determinados microrganismos. 


\section{Referências}

Antunes, L. E. C., Carvalho, G. L., dos Santos, A. (2011). A cultura do morango. Área de Informação da Sede-Col Criar Plantar ABC 500P/500R Saber (INFOTECA-E).

Asquieri, E. R., Rabêlo, A. M. D. S., \& Silva, A. G. D. M. (2008). Fermentado de jaca: estudo das características físico-químicas e sensoriais. Food Science and Technology, 28, 881-887.

Asquieri, E. R., Silva, A. G. D. M., \& Cândido, M. A. (2009). Aguardente de jabuticaba obtida da casca e borra da fabricação de fermentado de jabuticaba. Food Science and Technology, 29, 896-904.

BRASIL. Ministrério da Agricultura, Pecuária e Abastecimento. (2009). Decreto n o 6.871, de 04 de junho de 2009. Regulamenta a Lei n. 8.918, de 14 de julho de 1994, que dispõe sobre a padronização, a classifi cação, o registro, a inspeção, a produção e a fiscalização de bebidas.

Carvalho, S. F. D. (2013). Produção, qualidade e conservação pós-colheita de frutas de diferentes cultivares de morangueiro nas condições edafoclimáticas de Pelotas-RS (Master's thesis, Universidade Federal de Pelotas).

Fagundes, D. T. O., Silveira, M. L. R., Santos, C. O., Sautter, C. K., \& Penna, N. G. (2015). Fermentado alcoólico de fruta: uma revisão. $5^{\circ}$ Simpósio de Segurança Alimentar.

Januszek, M. et al. (2020). Saccharomyces bayanus Enhances Volatile Profile of Apple Brandies. Molecules, 25(14), 3127.

Lees, D. H., \& Francis, F. J. (1972). Standardization of pigment analyses in cranberries. HortScience.

Özcan, A. S., \& Özcan, A. (2004). Adsorption of acid dyes from aqueous solutions onto acid-activated bentonite. Journal of colloid and interface science, 276(1), 39-46.

Pessenti, I. L., Ayub, R. A., Botelho, R. V. (2019). Defoliation, application of S-ABA and vegetal extracts on the quality of grape and wine Malbec cultivar. Revista Brasileira de Fruticultura. 41(3).

Pessenti, I. L., Ayub, R. A., Melo, H. F., Martins, W. S., Wiecheteck, L. H., Botelho, R. V. Qualidade fenólica em cultivares de uva submetida a poda verde e regulador hormonal. Research, Society and Development, 10(4), e39310414227. DOI: 10.33448/rsd-v10i4.14227.

R Core Team. (2021). R: A Language and Environment for Statistical Computing. Vienna, Austria: R Foundation for Statistical Computing.

Santos, S. et al. (2005). Elaboração e análise sensorial do fermentado de acerola (Malpighia punicifolia L.). Brazilian Journal of Food Technology, v. 10, p. $47-50$.

Silva, P. H. A. D., Faria, F. C. D., Tonon, B., Mota, S. J. D., \& Pinto, V. T. (2008). Avaliação da composição química de fermentados alcoólicos de jabuticaba (Myrciaria jabuticaba). Quimica Nova, 31, 595-600.

Singleton, V. L., Rossi, J. A. (1965). Colorimetry of total phenolics with phosphomolybdic-phosphotungstic acid reagents. American journal of Enology and Viticulture, 16(3), 144-158.

Song, H. et al. (2016). The Effect of Fermentation Conditions on the Antioxidant Activity of Strawberry Wine. Journal of Xuzhou Institute of Technology (Natural Sciences Edition), (2), 16.

Tarko, T. et al. (2018). The effect of apple cultivars and yeast strains on selected quality parameters and antioxidant activity of fermented apple beverages. CyTA-Journal of Food, 16(1), 892-900.

Tessaro, D. et al. (2010). Avaliação das fermentações alcoólica e acética para produção de vinagre a partir de suco de laranja. Acta Scientiarum. Technology, $32(2)$. 